\title{
Causes of Treatment Abandonment of Pediatric Cancer Patients - Experience in a Regional Cancer Centre in North East India
}

\author{
Munlima Hazarika ${ }^{1}$, Rakesh Mishra ${ }^{1}$, Bhargab Jyoti Saikia ${ }^{1}$, Chidananda \\ Bhuyan $^{1}$, C W Nyuthe ${ }^{1}$, Anupam Sarma ${ }^{2}$, Gaurav Kumar ${ }^{1}$, Cliffton Sutnaga ${ }^{1}$, \\ Manoj Kalita ${ }^{3}$, Partha Roy ${ }^{1 *}$
}

\begin{abstract}
Introduction: Refusal and abandonment of treatment is often considered as an important reason for poor survival of pediatric cancer patients in developing and underdeveloped countries. In this study we analyze the factors responsible for treatment abandonment and refusal in a Regional Cancer Centre (RCC) in North East India. Material and Methods: All histopathologically or cytologically confirmed cases of childhood cancer from below 15 years of age registered from 1st April, 2010 to 31st March, 2017 were included in this study. Parents or caregivers were interviewed thoroughly and a questionnaire was filled up for analysis of demographic and socio-economic factors. Modified Kuppuswamy scale was used to measure socioeconomic status. Results: Of 592 patients $161(27.1 \%)$ abandoned therapy and $23(3.9 \%)$ refused treatment. Factors associated with abandonment of treatment included: lower risk if residing in urban areas (Odds ratio $[\mathrm{OR}]=0.8333,95 \% \mathrm{CI} 0.565-1.228 ; \mathrm{P}=0.36$ ) and higher risk with maternal education less than secondary school $(\mathrm{OR}=1.357 ; 95 \% \mathrm{CI}$ : 0.553-3.326; $\mathrm{P}=0.505)$. Low socioeconomic status and age $>5 \mathrm{yrs}$ were also associated with abandonment of treatment. In a binary logistic regression analysis, male sex [Odds Ratio $(\mathrm{OR})=0.701 ; 95 \% \mathrm{CI}$ 0.48-1.01; $\mathrm{P}=0.062]$ have lowest risk of abandoning treatment with trend to statistical significance. Conclusion: There is a need for proper definition of the problem of childhood cancer patients so that appropriate policy can be introduced to improve survival by improving treatment compliance.
\end{abstract}

Keywords: Pediatric cancer- treatment abandonment- treatment refusal- survival

Asian Pac J Cancer Prev, 20 (4), 1133-1137

\section{Introduction}

With the advancement in diagnosis, treatment and supportive care in pediatric patients with cancer, there have been dramatic improvement in survival rates in developed nations, where $80 \%$ of the children with cancer achieve cure (Stiller et al., 2007; Mattesini et al., 2010). But picture is not so promising in developing and underdeveloped countries, which accounts for $70 \%-80 \%$ of the nearly 2,50,000 newly diagnosed childhood cancer cases each year; and, often less than $25 \%$ of them surviving (Kellie et al., 2008; Riberio et al., 2008). Refusal and abandonment of treatment is often considered as an important reason for inferior survival outcome in childhood cancers in low and middle income countries (Arora et al., 2007; Bonilla et al., 2009). In this study we have tried to analyze the factors responsible for treatment abandonment and refusal in a Regional Cancer Centre (RCC) in North East India since these were suspected to be major causes of treatment failure (Hazarika et al., 2014). We analyzed the association of demographic and disease related factors with increased risk of abandonment and refusal of treatment.

\section{Materials and Methods}

Retrospective exploratory descriptive analysis was done after obtaining permission from Institutional Ethical Committee (IEC/BBCI-TMC/3187/2018)) of Dr. B Borooah Cancer Institute (BBCI), Guwahati, Assam, India, where hospital based cancer registration is going on actively since 2010 .

\section{Objectives of the study}

To analyze the association of demographic and disease related factors with increased risk of abandonment and refusal of treatment in patients with childhood cancer.

${ }^{1}$ Department of Medical Oncology, ${ }^{2}$ Department of Pathology, ${ }^{3}$ Population Based Cancer Registry, National Cancer Registry Programme (ICMR), Dr. B Borooah Cancer Institute, Gopinath Nagar, Guwahati, Assam, India. *For Correspondence:drpsr.roy@rediffmail.com 


\section{Inclusion criteria}

All histopathologically or cytologically confirmed cases of childhood cancer below 15 years of age registered at our institution from $1^{\text {st }}$ April, 2010 to $31^{\text {st }}$ March, 2017 and had completed their diagnostic workup were included for the study.

\section{Exclusion criteria}

Those with incomplete workup, previous diagnosis of cancer and who received any cancer directed treatment at other institute were excluded from the study.

Diagnostic criteria were specific for different cancers as per institutional protocol. Compilation of the data was started from $1^{\text {st }}$ April 2018 and analysis was done on July 2018.

Gender, age, maternal education and socioeconomic status were included for measures. Demographic and socioeconomic factors including age, gender, occupation, family income and education were retrieved from Hospital based cancer registry, which was recorded at the time of hospital registration. Age groups were divided between age $\leq 5$ yrs and $>5$ yrs. Place of residence was grouped into rural and urban. Maternal education was grouped into more than secondary school and less than secondary school education. Socioeconomic status was calculated by modified Kuppuswamy scale (Annexure 1) and divided into two groups one with total score $>10$ (middle and upper class) and another with score $\leq 10$ (upper lower and lower class). Parents or caregivers were interviewed thoroughly telephonically and a questionnaire was filled up for causes of treatment abandonment analysis. On the basis of medical record review from patients, treatment outcome for each patient was categorized as: (1) completed or presently undergoing treatment; (2) refused treatment; (3) abandoned treatment/loss to follow up; or (4) death from any cause.

Abandonment of treatment was defined as the termination of care by the parent/caregiver and/or not presenting for scheduled treatment for four weeks or more from the scheduled date of treatment at the time of data record in line with International Society of Pediatric Oncology (SIOP) recommendation (Mostert et al., 2011). If a child returned for treatment after 4 weeks, he/she was considered in treatment abandonment group for analysis. Refusal of treatment was defined as no initiation of treatment after the complete diagnosis of cancer.

\section{Statistical Analyses}

Data management and analysis was done using SPSS version 19. A descriptive analysis for each factor was done. Difference in socio-demographic and clinical characteristics between treatment abandonment and treatment non abandonment were analyzed using $\chi^{2}$ tests. To verify factors that affected treatment abandonment, a binary logistic regression analysis was done. Two tailed p-values less than 0.05 were considered statistically significant at $95 \%$ confidence interval.

\section{Results}

The median age at presentation was 7 years and mean age was 7.4 years ( $\mathrm{SD} \pm 4.8)$. The male: female ratio was 1.5: 1 in entire population. In our observation, out of 592 patients, $161(27.1 \%)$ patients abandoned therapy and 23 (3.9\%) patients refused treatment. Seventy two (31.2\%) of 231 female patients abandoned treatment, whereas, $89(24.7 \%)$ of 361 male patients abandoned treatment (Table 2), suggesting that more female patients tended to abandoned therapy.

Other factors associated with abandonment of treatment included: lower risk in patients who were residing in urban areas versus those residing in rural areas [Odds ratio, $(\mathrm{OR})=0.8333$; 95\% CI: 0.565-1.228; $\mathrm{P}=0.36]$; and higher risk in patients with maternal education less than secondary school versus those with maternal education more than secondary school education $(\mathrm{OR}=1.357 ; 95 \% \mathrm{CI}: 0.553-3.326 ; \mathrm{P}=0.505)$. Children coming from low socioeconomic status and age $>5 \mathrm{yrs}$ were also associated with abandonment of treatment (Table 2). In a binary logistic regression analysis including gender, age, residence, socioeconomic status and maternal education, the associations with male sex $(\mathrm{OR}=0.701$; 95\% CI 0.48-1.01; $\mathrm{P}=0.062$ ) had lowest risk of abandoning treatment with trend to statistical significance (Table 2).

In our observation, $46(28.6 \%)$ patients abandoned treatment due to poor financial condition, 36 (22.4\%) due to progressive disease and $20(12.4 \%)$ due to long travelling distance. In our study, only $8(4.9 \%)$ patients abandoned therapy due to treatment related toxicity, whereas, $3(1.9 \%)$ patients went to other centers (Table 3 ).

Table 1. Demographic and Treatment Characteristics

\begin{tabular}{|c|c|c|}
\hline Variables & $\begin{array}{l}\mathrm{N}=592 \\
(\%)\end{array}$ & $\begin{array}{c}\text { Median } \\
(\text { Mean } \pm \text { SD) }\end{array}$ \\
\hline \multicolumn{3}{|l|}{ Sex } \\
\hline Male & $361(60.9)$ & \\
\hline Female & $231(39.1)$ & \\
\hline Age at diagnosis (in years) & - & $7(7.4 \pm 4.8)$ \\
\hline \multicolumn{3}{|l|}{ Age (in years) } \\
\hline$>5 \mathrm{yrs}$ & $331(55.9)$ & \\
\hline$\leq 5 \mathrm{yrs}$ & $261(44.1)$ & \\
\hline \multicolumn{3}{|l|}{ Maternal education } \\
\hline More than secondary school & $34(5.7)$ & \\
\hline Less than secondary school & $551(93.1)$ & \\
\hline Unknown & $7(1.2)$ & \\
\hline \multicolumn{3}{|l|}{ Residence } \\
\hline Rural & $385(65)$ & \\
\hline Urban & $207(35)$ & \\
\hline \multicolumn{3}{|c|}{ Modified Kuppuswamy Scale score } \\
\hline $\begin{array}{l}\text { Upper lower and lower class } \\
\text { (score } \leq 10 \text { ) }\end{array}$ & $467(78.9)$ & \\
\hline $\begin{array}{l}\text { Upper and middle class } \\
(\text { score }>10)\end{array}$ & $125(21.1)$ & \\
\hline Treatment abandonment & $161(27.1)$ & \\
\hline Treatment refused & $23(3.9)$ & \\
\hline
\end{tabular}


Table 2. Binary Logistic Regression Analysis of Biological and Socioeconomic Variables as Predictors for Treatment Abandonment

\begin{tabular}{|c|c|c|c|c|c|}
\hline Variables & $\begin{array}{c}\text { Treatment } \\
\text { abandonmentn }(\%)\end{array}$ & $\begin{array}{c}\text { Non treatment } \\
\text { abandonment n (\%) }\end{array}$ & $\begin{array}{l}\text { Odds ratio } \\
\text { (OR) }\end{array}$ & $95 \% \mathrm{CI}$ & $\begin{array}{c}\mathrm{P} \\
\text { value }\end{array}$ \\
\hline \multicolumn{6}{|l|}{ Sex } \\
\hline Female & $72(44.7)$ & $159(36.9)$ & 1 & $0.483-1.018$ & 0.062 \\
\hline Male & $89(55.3)$ & $272(63.1)$ & 0.701 & & \\
\hline \multicolumn{6}{|l|}{ Age at diagnosis (in years) } \\
\hline$>5 \mathrm{yrs}$ & $95(59)$ & $236(54.8)$ & 1 & $0.576-1.220$ & 0.358 \\
\hline$<5$ yrs & $66(41)$ & $195(45.2)$ & 0.839 & & \\
\hline \multicolumn{6}{|l|}{ Maternal education } \\
\hline More than secondary school & $7(4.5)$ & $27(6.3)$ & 1 & & \\
\hline Less than secondary school & $150(95.5)$ & $401(93.7)$ & 1.357 & & \\
\hline \multicolumn{6}{|l|}{ Residence } \\
\hline Rural & $100(62.1)$ & $285(66.1)$ & 1 & $0.565-1.228$ & 0.356 \\
\hline Urban & $61(37.9)$ & $146(33.9)$ & 0.8333 & & \\
\hline \multicolumn{6}{|l|}{ Modified Kuppuswamy scale score } \\
\hline Upper lower and lower class ( score $\leq 10$ ) & $130(80.7)$ & $337(78.2)$ & 1 & $0.544-1.434$ & 0.616 \\
\hline Upper and middle class (score >10) & $31(19.3)$ & $94(21.8)$ & 0.883 & & \\
\hline
\end{tabular}

Table 3. Reasons of Treatment Abandonment

\begin{tabular}{lc}
\hline $\mathrm{n}=161(\%)$ & \\
\hline Poor financial condition & $46(28.6 \%)$ \\
Progressive disease & $36(22.4 \%)$ \\
Long distance to treatment centre & $20(12.4 \%)$ \\
Unknown & $48(29.8 \%)$ \\
Toxicity & $8(4.9 \%)$ \\
Went to other centre & $3(1.9 \%)$ \\
\hline
\end{tabular}

In $48(29.8 \%)$ patients reason for treatment abandonment remains unknown (these includes patients who were not traceable and those who refused to participate in the study).

The reasons for treatment refusal in our study were found to be long travelling distance from the area of residence to treatment center in $11(47.8 \%)$ patients and poor financial status in $6(26.1 \%)$ patients (table 4$)$.

\section{Discussion}

In our study, $27.1 \%$ of the patients abandoned treatment, which is consistent with other studies in developing countries where treatment abandonment were around 25-50\% (Metzger et al., 2003; Meremikwu et al., 2005; Moster et al., 2006; De Boer et al., 2009; Mostert et al., 2010; Sitaresmi et al., 2010; Moster et al., 2012).

We did not find any statistically significant association of age group, residence, maternal education to affect treatment abandonment. Though majority of our patients belonged to lower socioeconomic class, this also did not appear to influence the treatment abandonment. However, we observe a trend for higher abandonment rate in female child which may be due gender inequality in Indian society favoring male child.

Various reasons for abandonment of treatment are
Table 4. Reasons of Treatment Refusal

\begin{tabular}{lc}
\hline $\mathrm{n}=23(\%)$ & \\
\hline Long distance to treatment centre & $11(47.8 \%)$ \\
Poor financial condition & $6(26.1 \%)$ \\
Unknown & $6(26.1 \%)$ \\
\hline
\end{tabular}

observed in different studies, most common being financial constraints and lack of parental education (Meremikwu et al., 2005; Arora et al., 2007; Jeremy et al., 2014). Monthly income of the family has also been shown to be significantly related to abandonment rate (Yadav et al., 2007; Bonilla et al., 2009). In our study $80.7 \%$ of the patients who abandoned treatment, the parents belonged to lower and upper lower socio-economic status by modified Kuppuswamy scale (Annexure: 1) (Kumar et al., 2007). We also observed more treatment abandonment if the mother had less than secondary school education. Similar finding were seen by Sachdeva et al., (2005) who reported that parents of children who abandoned treatment were found to have limited education and economic means.

Cost of transport and distance from treatment centre also contributes to treatment abandonment (Bonilla et al., 2009; Arora et al., 2010; Sitaresmi et al., 2010). Long distance from treatment centre was amongst the commonest reasons for treatment abandonment and also treatment refusal in our study. This may be because of many factors, including, poor connectivity of road and public transport due to difficult geographical location and the amount of time and money required to travel to the treatment center. Our hospital is the only tertiary cancer care centre for pediatric oncology in entire North-East India, where majority of the families seeking treatment had to travel more than $100 \mathrm{~km}$ distance. Opening satellite center, providing transportation cost with free lodging facility are few of the measures that can be done to reduce treatment abandonment and refusal. In 
Brazil, abandonment of treatment was nearly eliminated over a period of 20 years by providing lodging, food, and transportation assistance to patients with acute lymphoblastic leukemia (ALL) (Howard et al., 2004).

We observed that in patients belonging to rural areas treatment abandonment were higher (62\%) as compared to patients coming from urban area, which may be due to long distance to travel or more frequent use of alternative mode of therapy. An Indian study by Kumar et al., (2013) in Retinoblastoma patients also showed more treatment abandonment in rural areas as seen in our study.

Age has been variably reported as being associated with treatment abandonment. In our study age more than 5 years was associated with more treatment abandonment. In contrast, Metzger et al., (2003) reported an association of abandonment with age less than 4.5 years in a cohort of children with ALL. However Arora et al., (2010) did not find any such association in cohort of patients from India.

The percentage of male seeking healthcare was higher as compared to female in our study. When we analyzed gender as a separate factor, there was more treatment abandonment in female child. Similarly in a follow-up survey from Northern India, 28\% of parents reported that the patient being a female influenced their decision for treatment abandonment (Arora et al., 2010).

Twenty three (3.9\%) patients refused treatment in our study. This is comparatively less as compare to another study from a tertiary healthcare establishment in India, in which out of 762 children with ALL, 30\% refused treatment (Kulkarni et al., 2009). This difference could be attributed to different disease population between these two studies. Refusal of treatment initiation is also a major cause of poor survival in pediatric cancer patients. In a study from Indonesia, it was seen that, after introduction of a parental education program to increase the access to information about leukemia for ALL patients, treatment refusal decreased from 14 to $2 \%$, with improvement in survival (Mostert et al., 2010). Hence, improving systematic health education program with improvement of diagnostic evaluation facilities could have direct impact on reducing refusal rate.

Our study being retrospective one has got various limitations. As it was done after several years of diagnosis, we were unable to contact nearly one third families due to missing or outdated contact details in medical records and some declined to participate. Another limitation of this study includes the reliance on self-reported measures and recall bias. Other confounding factors like faith, cultural issues and communication between parents and health care provider may affect decision of treatment abandonment. Another drawback was to indentify best indicator for socioeconomic status as social transformation and fast-growing economy have rendered these scales ineffective. Socioeconomic measure used in our study (modified Kuppuswamy scale) also has limitations as there is an overemphasis on income rather than educational and occupational factors.

Even with these limitations, it is apparent that treatment abandonment is a complex issue. Also factors affecting abandonment in one population may not be applicable to another population. As such it is necessary to identify these factors to implement measures that reduce treatment abandonment and refusal. Provision of free treatment, better transport facility, and providing facility for accommodation will reduce economic burden to parents or other caregivers. There should be proper communication regarding systematic health education between parents and heath care providers with psychosocial support for health beliefs and experiences. It is also vital to track patients who did not report on timely visits for better compliance.

In conclusion, there is an urgent need for proper definition of the problem of childhood cancer patients to implement appropriate policy to improve adherence to treatment. This observation will throw light on the causes of refusal and abandonment of treatment which is the leading cause of treatment failure in pediatric cancer cases in the developing world. A properly planned prospective study will help in better understanding of the issues so as to improve treatment adherence and thereby improving outcome.

\section{References}

Arora RS, Eden T, Pizer B (2007). The problem of treatment abandonment in children from developing countries with cancer. Pediatr Blood Cancer, 49, 941-6.

Arora RS, Pizer B, Eden T (2010). Refusal and abandonment in childhood cancer. Indian Pediatrics, 47, 1005-10.

Bonilla M, Gupta S, Vasquez R, et al (2010). Predictors of outcome and methodological issues in children with acute lymphoblastic leukaemia in El Salvador. Eur J Cancer, 46, 3280-6.

Bonilla M, Rossell N, Salaverria C, et al (2009). Prevalence and predictors of abandonment of therapy among children with cancer in El Salvador. Int J Cancer, 125, 2144-6.

De Boer JD, Boellaard TN, Parkinson S, Blanchard E, Heij HA (2009). Patient compliance in the treatment of Burkitt's lymphoma in rural Zambia: a retrospective study on 80 Burkitt's lymphoma patients in Katete, Zambia. Afr $J$ Paediatr Surg, 6, 3-6.

Hazarika M, Krishnatreya M, Roy PS, et al (2014). Overview of childhood cancers at a regional cancer centre in North-East India. Asian Pac J Cancer Prev, 15, 7817-9.

Howard SC, Pedrosa M, Lins M, et al (2004). Establishment of a pediatric oncology program and outcomes of childhood acute lymphoblastic leukemia in a resource-poor area. JAMA, 291, 2471-5.

Slone JS, Chunda-Liyoka C, Perez M, et al (2014). Pediatric malignancies, treatment outcomes and abandonment of pediatric cancer treatment in Zambia. PLoS One, 9, e89102.

Kellie SJ, Howard SC (2008). Global child health priorities: what role for paediatric oncologists?. Eur J Cancer, 44, 2388-96.

Kulkarni K, Marwaha RK, Trehan A, Bansal D (2009). Survival outcome in childhood ALL: experience from a tertiary care centre in North India. Pediatr Blood Cancer, 53, 168-73.

Kumar N, Shekhar C, Kumar P, Kundu AS (2007). Kuppuswamy's socioeconomic status scale- Updating for 2007. Indian $J$ Pediatr, 74, 1131-2.

Kumar A, Moulik NR, Mishra RK, Kumar D (2013) Causes, outcome and prevention of abandonment in retinoblastoma in India. Pediatr Blood Cancer, 60, 771-5.

Mattesini M, Belonoshko AB, Buforn E, et al (2010). Hemispherical anisotropic patterns of the Earth's inner core. Proc Natl Acad Sci U S A, 107, 9507-12.

Meremikwu MM, Ehiri JE, Nkanga DG, et al (2005). 
Socioeconomic constraints to effective management of Burkitt's lymphoma in south-eastern Nigeria. Trop Med Int Health, 10, 92-8.

Metzger ML, Howard SC, Fu LC, et al (2003). Outcome of childhood acute lymphoblastic leukaemia in resource-poor countries. Lancent, 362, 706-8.

Mostert S, Arora RS, Arreola M, et al (2011). Abandonment of treatment for childhood cancer: position statement of a SIOP PODC Working Group. Lancet Oncol, 12, 719-20.

Mostert S, Gunawan S, Wolters E, et al (2012) Socio-economic status plays important roles in childhood cancer treatment outcome in Indonesia. Asian Pac J Cancer Prev, 13, 6491-6.

Mostert S, Sitaresmi MN, Gundy CM, et al (2010). Comparing childhood leukaemia treatment before and after the introduction of a parental education programme in Indonesia. Arch Dis Child, 95, 20-5.

Mostert S, Sitaresmi MN, Gundy CM, Sutaryo, Veerman AJ (2006). Influence of socioeconomic status on childhood acute lymphoblastic leukemia treatment in Indonesia. Pediatrics, 118, e1600-6.

Ribeiro RC, Steliarova-Foucher E, Magrath I, et al (2008) Baseline status of paediatric oncology care in ten low-income or mid-income countries receiving My Child Matters support: a descriptive study. Lancet Oncol, 9, 721-9.

Sachdeva A, Jain V, Yadav SP, et al (2005). Move to alternative medicine why and when? The Indian scenario [abstract]. Pediatr Blood Cancer, 45, 578.

Sitaresmi MN, Mostert S, Schook RM, Veerman AJ (2010). Treatment refusal and abandonment in childhood acute lymphoblastic leukemia in Indonesia: an analysis of causes and consequences. Psychooncology, 19, 361-7.

Stiller C (2007). Childhood cancer in Britain: Incidence, survival, mortality. Oxford: Oxford University Press; 2007.
Yadav S, Anjan M, Sachdeva A (2007). Outcome of children with haematological malignancies who are lost to follow up [abstract]. Pediatr Blood Cancer, 49, 527-9.

This work is licensed under a Creative Commons AttributionNon Commercial 4.0 International License. 